Int. J. Dev. Biol. 56: 969-974 (2012)

doi: $10.1387 / \mathrm{ijdb} .120172 \mathrm{fn}$

\title{
Gliomatosis peritonei as a natural experiment in tissue differentiation
}

\author{
FRANCISCO F. NOGALES ${ }^{*, 1}$, OVIDIU PREDA ${ }^{2}$ and ISABEL DULCEY ${ }^{1}$ \\ ${ }^{1}$ Department of Pathology, San Cecilio University Hospital, Granada and ${ }^{2}$ Master Diagnostica, Granada, Spain
}

\begin{abstract}
Gliomatosis peritonei (GP) is an unusual condition in which nodules of mature astroglia, often miliary and microscopic in size, are widespread in the peritoneum and abdominal lymph nodes. Its behaviour is benign and it is usually found in association with ovarian teratoma and rarely with teratomas of other organs. Implants grow rapidly and can remain unchanged for life. Astroglia is the main component, but other neural lineage elements and many other tissues can be found. Cells are mature but not terminal, since they express SOX2. Secondary associated lesions include: a) degenerative astrocytic changes, b) granulomatous and follicular chronic inflammatory changes, c) association with hormonally related changes, such as decidual peritoneal metaplasia and endometriosis and d) endothelial and adventitial vascular hyperplasia leading to haemoperitoneum. Two pathogenetic mechanisms are considered: direct seeding of immature neural cells from a primary tumour with subsequent differentiation and metaplasia from peritoneal stem cells. The former proposal is supported by clinicopathologic data such as ample cellular heterogeneity, coexistence of mature astroglia with neural blastema, as well as the shed keratin and hairs from the ovarian neoplasm. However, metaplasia is sustained by a heterozygosity pattern of GP nodules, identical to the normal tissue and different from the coexistent ovarian teratoma. GP would constitute a response to growth factors from teratoma or macrophages. While an implantative origin from ovarian teratoma remains in most cases a more probable mechanism, metaplasia from peritoneal stem cells would explain cases of GP which present a monomorphic astrocytic cell population.
\end{abstract}

KEY WORDS: gliomatosis peritonei, ovary, teratoma, ectopic glia, SOX2

\section{Introduction}

Gliomatosis peritonei (GP) is an unusual condition consisting in the presence of multiple nodules of mature astrocytes in the serosal peritoneal surface of the abdominal cavity. Although its clinical picture of peritoneal spread is that of advanced stage neoplasia, its behaviour is almost invariably benign, since its differentiated cells lack proliferative activity (Fortt et al., 1969; Nogales et al., 1974; Robboy et al., 1970).

The majority of cases of GP are associated with an immature ovarian teratoma and only rarely with mature teratomas (Dhingra et al., 2007; Gocht et al., 1995); albeit a rare phenomenon, it can occur in up to a fourth of all cases of ovarian immature teratoma. Although GP has been reported in association with isolated cases of teratomas of the stomach, liver and bladder (Karlo et al., 2009; Torikai et al., 2007; Yeo et al., 2010), such exceptional cases do not really conform to the classic picture of miliary peritoneal spread of GP that occurs with ovarian teratoma; instead they are large, circumscribed masses more suggestive of usual-type metastases.

Traditionally, the association with a concomitant neoplasm has favoured the hypothesis of GP as a phenomenon of implantation and subsequent maturation of neural precursor cells detached from the primary tumour. However, in the female peritoneum, the presence of ectopic benign tissues such as serous tubal epithelium is extremely frequent. Exceptionally, numerous nodules of highly differentiated thyroid tissue may be found in the peritoneum; the so called benign strumosis (Karseladze et al., 1994), which may occur in association with struma ovarii. Also, well differentiated Sertoli cell tumours can implant foci of benign immature Sertoli-cell tubules in the peritoneum (Onida et al., 2010). The pathogenesis of these mature ectopic tissues is not clear and both mechanisms of direct seeding/differentiation from a primary tumour (Robboy et al., 1970) and peritoneal metaplasia (Ferguson et al., 2001) from stem cells have been proposed.

Abbreviations used in this paper: GP, gliomatosis peritonei.

*Address correspondence to: Francisco F. Nogales. Department of Pathology. San Cecilio University Hospital, 18012 Granada, Spain. E-mail: fnogales@ ugr.es

Final, author-corrected PDF published online: 5 February 2013.

ISSN: Online 1696-3547, Print 0214-6282

(c) 2013 UBC Press

Printed in Spain 
In this review we will focus on the clinical and histological features of GP, with special consideration of its histogenesis, which may include two alternative mechanisms.

\section{Clinical features}

GP affects a broad age range, from childhood to postmenopausal patients, with a peak in the second and third decades of life and only few instances above the age of sixty. Often occurring as an incidental finding during surgery for ovarian tumour or in second look operations after a diagnosis of teratoma, it is consistently associated with a unilateral solid tumour. GP may occur after capsular rupture during surgery or spontaneously. When oophorectomy alone is performed without accompanying salpingectomy, there is a high chance of rupturing the capsule at the ovarian pedicle at hilar level.

The overall prognosis of GP is excellent and chemotherapeutic treatment is unnecessary. Long follow-up studies have demonstrated its benign course (Fortt et al., 1969; Robboy et al., 1970). A recent study comparing ovarian immature teratomas with and without GP demonstrated a similar overall good survival but with a higher incidence of early recurrences in the cases associated with GP (Mann et al., 2008; Yoon et al., 2012). Occasionally, GP may precede highly malignant neuroectodermal tumours (Dadmanesh et al., 1997; Shefren et al., 1991; Trabelsi et al., 2002). Cases from the older literature reporting early malignant behaviour may correspond to recurrences of incompletely sampled peritoneal disease, with foci of immature tissue not identified at the time of surgery.

Implants can grow rapidly. In one instance, they were detected in a second look operation performed only one month after oophorectomy for immature teratoma (Nogales et al., 1974). In rare instances, such as another of our cases, PG can be an incidental autopsy finding of asymptomatic residual disease in elderly patients who had had ovarian teratoma in their youth.

Among serum markers, CA125 levels are elevated in GP (Yoon et al., 2012) and some authors (Bahari et al., 1980; de Graaff et al., 1980; Hokama et al., 1991) have also reported elevated alphafetoprotein levels, possibly related to endodermal elements present in the immature teratoma deposits.

\section{Pathology findings}

\section{Primary teratoma}

GP occurs in association with a unilateral solid ovarian teratoma. Histologically the primary tumour shows tissues with a variable degree of immaturity. However, the predominant tissue is of neural type and comprises large amounts of well differentiated glial tissue with other neuroectodermal components. Other frequent non-neurological constituents are skin, developing teeth, gastrointestinal derivatives although, eventually, any imaginable tissue can be found (Nogales et al., 2003).

Histological tumour grading of teratomas is a valuable tool for predicting their behaviour (Nogales et al., 1976; Norris et al., 1976; Thurlbeck et al., 1960). It is performed by a subjective, semiquantitative analysis of the relative number and atypicality of immature neural tissues present in the neoplasm such as neuroepithelial tubules and neural blastema. This is accomplished either by the traditional approach of assigning 4 grades ranging from fully mature (grade 0 ) to highly immature (grade 3 ) or by establishing a two tier system into low grade and high grade tumours (O'Connor et al.,
1994). Ovarian neoplasms associated with GP are most frequently of grade 1 or 2 and only rarely may correspond to grades 0 (fully mature) or 3 (highly immature). When found in association with grade 0 solid teratomas, the tumour warrants a more extensive tissue sampling in order to exclude any immature foci. Evaluation of immaturity can be enhanced by the immunohistochemical analysis of pluripotency markers such as SALL4 and SOX2 which are highly sensitive in the identification of neural immature cells (Nogales et al., 2012).

An interesting aspect of ovarian immature teratoma is the concomitant vascular response present in association with neural tissues. There is an extensive endothelial proliferation of vessels, similar to that occurring in tumours of the central nervous system, originating as a response to angiogenic factors secreted by immature neural elements (Baker et al., 2002; Nogales et al., 2002;

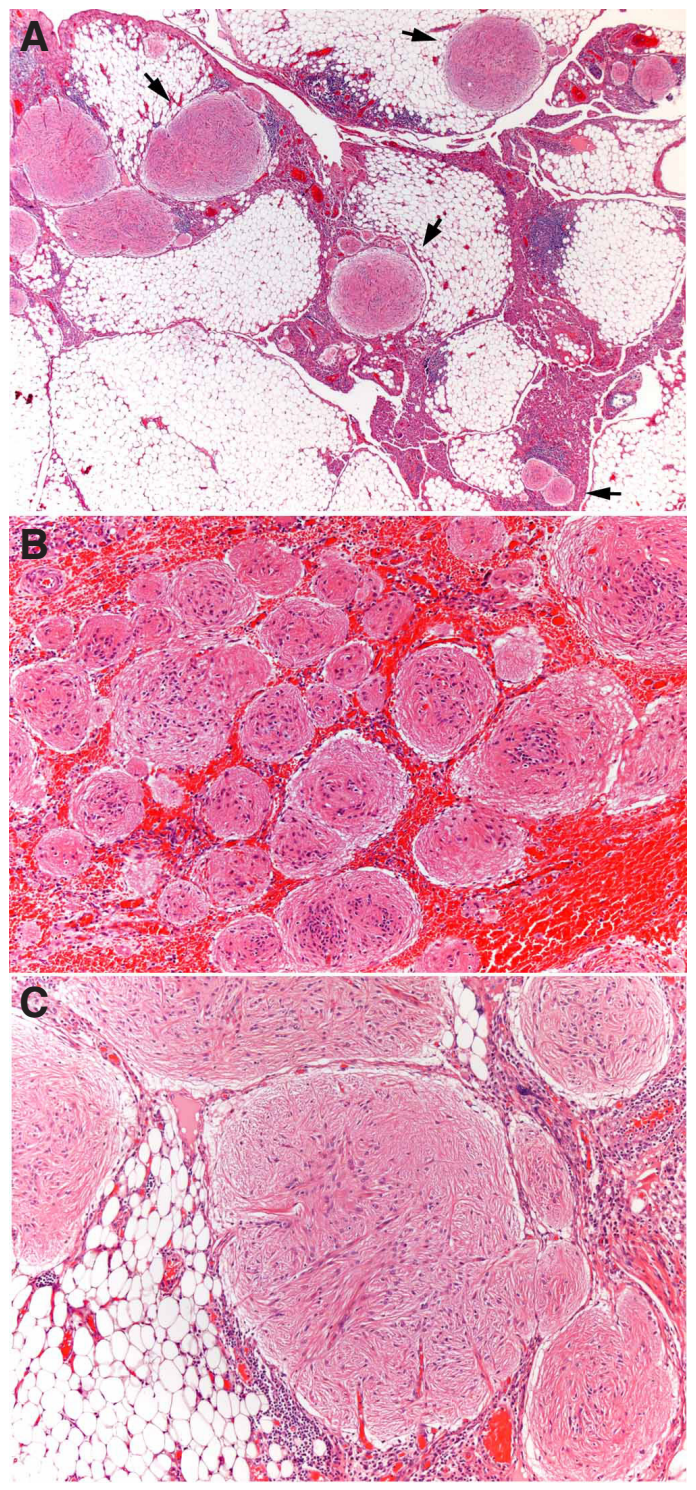

Fig. 1. Characteristic appearance of Gliomatosis peritonei (GP) at low power. Multiple astrocytic nodules (arrows) are scattered throughout the omental surface and underlying fatty tissue(A). Glial nodules are surrounded by haemorrhage (B). Higher magnification (C) reveals uniform, mature glial cells set in a fibrillary matrix. 
Nogales et al., 1983; Nogales et al., 1974). Only on rare occasions a secondary, highly malignant neural tumour, such as primitive neuroectodermal tumour (PNET) may develop from the stem cells present in ovarian immature teratoma. In these cases, metastases are always of high grade (Morovic et al., 2008).

\section{Gliomatosis peritonei}

Appears as miliary deposits scattered throughout the peritoneum involving every serosal surface including recesses, cul-de-sac, intestinal surface, etc. In a few cases the coexistence of adhesions due to endometriosis may give it a more complex appearance. Haemorrhage can be present in the nodules. Surgical sampling should be as extensive as possible in order to evaluate fully the immaturity of the peritoneal deposits. Chemotherapy will depend on grading of GP, being indicated for high grades and not administered in grade 0 implants.

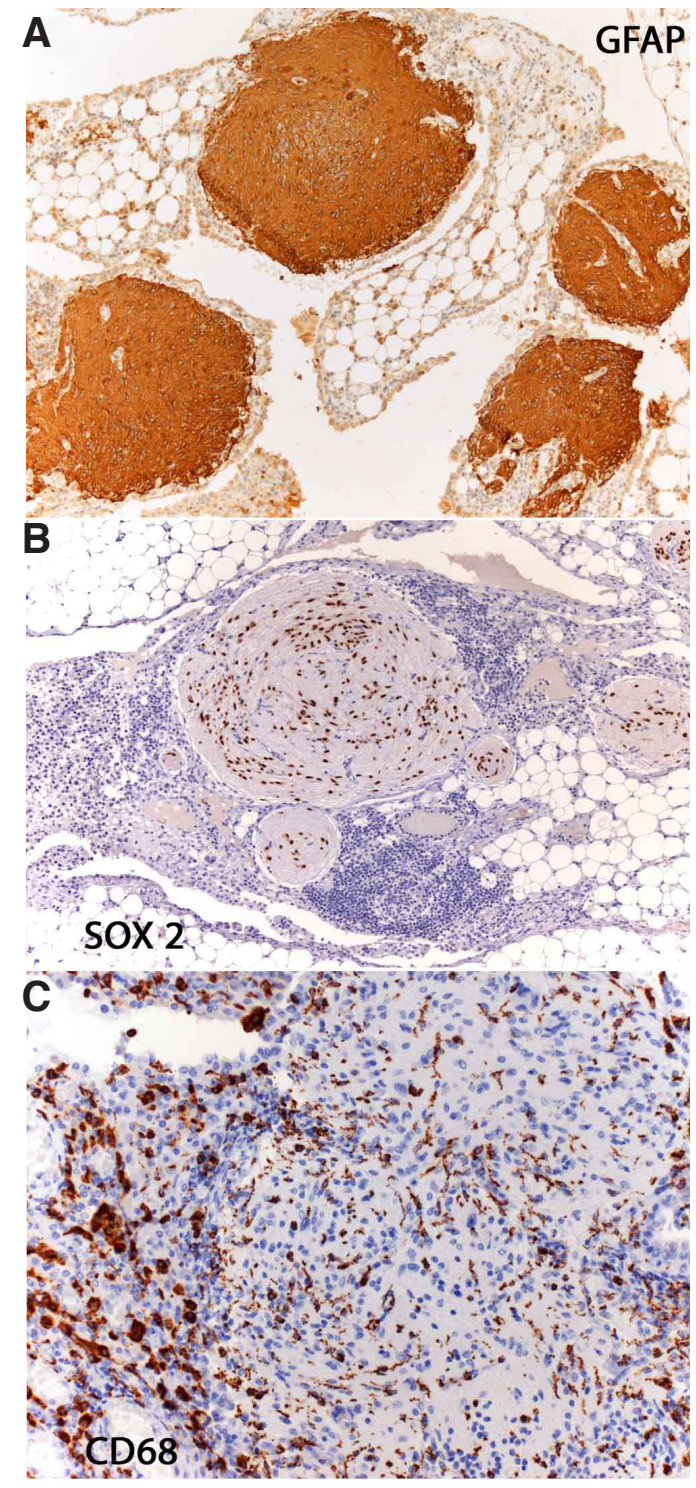

Fig. 2. Immunohistochemistry of Gliomatosis peritonei (GP). Nodules are intensely positive for glial fibrillary acidic protein (A). Nuclei, despite a mature appearance, express SOX2 (B). CD68 stains macrophages and intranodular stellate cells identical to microglia (C).
Macroscopically, GP appears as white or yellow nodules of variable size ranging from $1 \mathrm{~mm}$ to $1 \mathrm{~cm}$ and can be difficult to visualize. Indeed, they are often only microscopic and sometimes are an incidental finding in specimens from an omentectomy performed at the time of oophorectomy (Nogales et al., 1974). True GP should be differentiated from large, discrete nodules of peritoneal metastases.

Microscopically, nodules are scattered through the peritoneum (Figs 1A,B) and composed of a glial cell population with mature features, minimal atypia and only rare mitoses. The predominant cell types are fibrous astrocytes (Fig 1C) staining for glial fibrillary acidic protein (Fig 2A). Their nuclei do not express pluripotency gene SALL4 protein, which is present in immature neural tissue (Ma Y.2012, Nogales et al., 2012) but are positive for SOX2 (Fig 2B), a pluripotency transcription factor involved in neurogenesis (Noisa et al., 2012), indicating that cells are mature but not terminally differentiated cells. Ultrastructurally, presence of other neural lineages such as oligodendroglia, ependymal, melanocytic and even neurons is demonstrated (Gonzalez-Campora et al., 1979). Immunohistochemically, the NeuN neuronal nuclear antibody often shows scattered positive neuronal cells. Additionally, we have been able to detect the presence of CD68 positive microglia-like cells in the GP nodules (Fig 2C).

There are instances where the coexistence of foci of immature neuroepithelium with a mature glia is indicative of its differentiation from immature precursors (Fig 3A). Other non-neural tissue

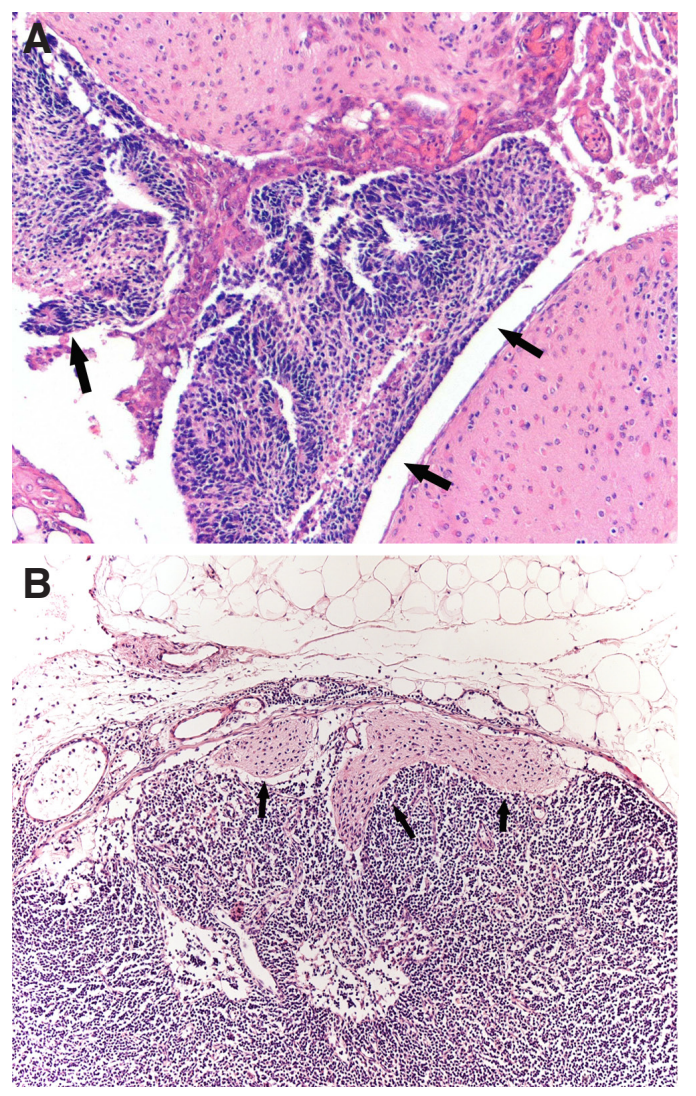

Fig. 3. Mature glial nodules (gliomatosis peritonei) may coexist with foci of immature neural tissue exhibiting neuroepithelial tubules (arrows) (A). Gliomatosis peritonei (GP) (arrow) is present in the marginal sinus of an abdominal lymph node (B) 
components such as epidermis, cartilage, respiratory and digestive tract epithelia may also be present in the nodules.

GP involvement of lymph nodes (Heifetz et al., 1998; Mann et al., 2008; Muller et al., 2002) is often an incidental finding in abdominal lymphadenectomy specimens, occurring in the marginal sinus (Fig 3B).

Secondary associated lesions in GP may include the following:

1. Degenerative changes in the GP astrocytes such as Rosenthal fibres, granular gemistocytes (Fig 4A), corpora amylacea etc.

2. Inflammatory changes: Chronic inflammation, frequently with follicular formation, is a common phenomenon around GP nodules (Fig 4B). Granulomatous reaction of foreign-body type occurs in relationship with keratin-rich desquamated epidermis or hairs (Fig 4C,D). In cases of long standing GP, a chronic macrophagic reaction can practically overgrow and erase the glial component.

3. Hormonal changes such as decidual transformation of mesothelium can also arise in the neighbouring peritoneum in cases of GP occurring during pregnancy (Fig 4E).

4. Vascular hyperplasia occurs in the vicinity of the nodules exhibiting a complex glomeruloid appeareance due to the proliferation of endothelial and adventitial vascular cells (Nogales et al., 2002) (Fig 4F). These fragile, irregular vessels can be the source of hemoperitoneum.

5. Post-chemotherapy changes reveal degenerative nuclei in astrocytic cells (Fig 4G).

6. Endometriosis. Foci of endometrial tissue displaying both glands and stroma can coexist in the ovarian surface and peritoneum, where isolated glands are surrounded by GP. However, no cases of coexistence of leiomyomatosis peritonealis disseminata or endosalpingiosis/endocervicosis have been reported in GP (Fig 4H).

\section{Pathogenesis}

It is by no means clear. Two alternative mechanisms of differentiation have been proposed:

Fig. 4. Secondary changes in Gliomatosis peritonei (GP). Presence of granular gemistocytes (A). Chronic lymphocytic, follicular (F) infiltration around a GP nodule (arrow) (B). Coexistence of GP with keratin peritoneal deposits (arrow) (C). A GP nodule coexists with teratomatous hairs from ovarian primary (arrows) (D). Decidual peritoneal change $(D E C)$ in a pregnant patient coexists with GP(E). Florid vascular hyperplasia in a case associated with haemoperitoneum(F). Postchemotherapy glial atypia (G). Coexistence of GP with numerous embedded fociof ectopic endometrium (arrows) (H).

\section{Peritoneal implantation}

The aetiology of GP has been related, since its initial description (Robboy et al., 1970), to implantation of immature neural tissue into the peritoneum subsequent to capsular rupture, either spontaneous or surgical. Thus there would be seeding of immature precursors that eventually differentiate into benign, terminally differentiated cells, including glia.

Data supporting this possibility include the following:

a) GP nodules do not only contain glia, but several other neurogenic lines (Gonzalez-Campora et al., 1979) and other tissues such as skin, gut, cartilage etc. This ample range of differentiation is characteristic of teratoma. Furthermore, immature neuroepithelial tubules may coexist with other neural cell lines
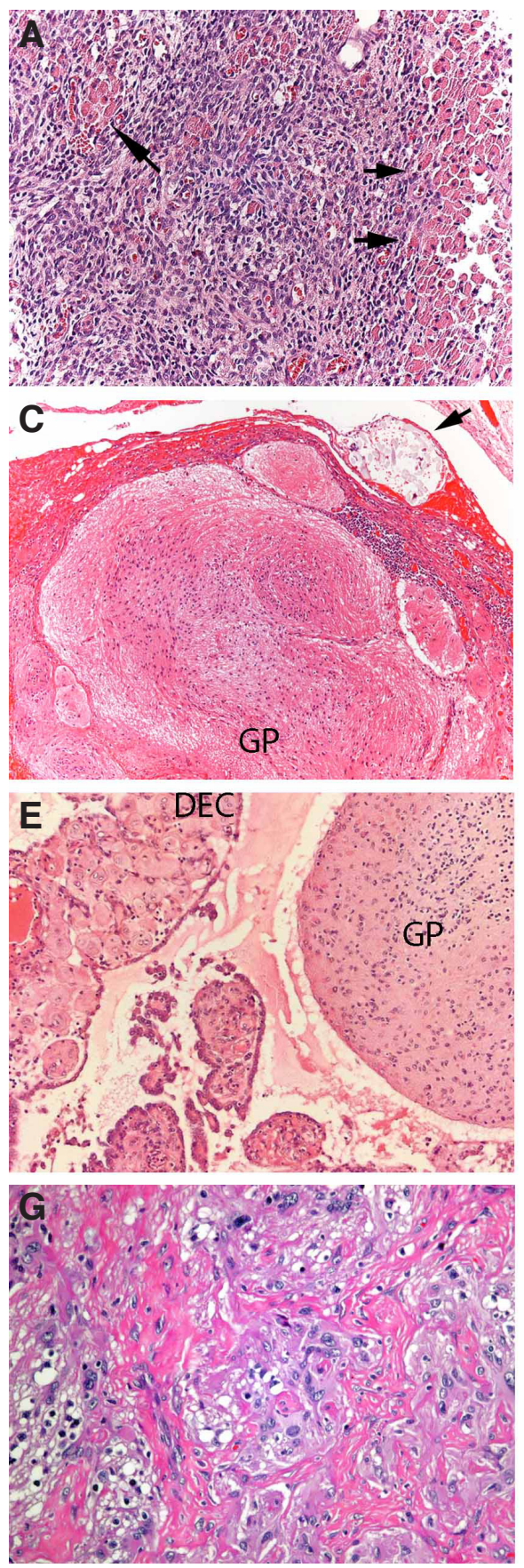
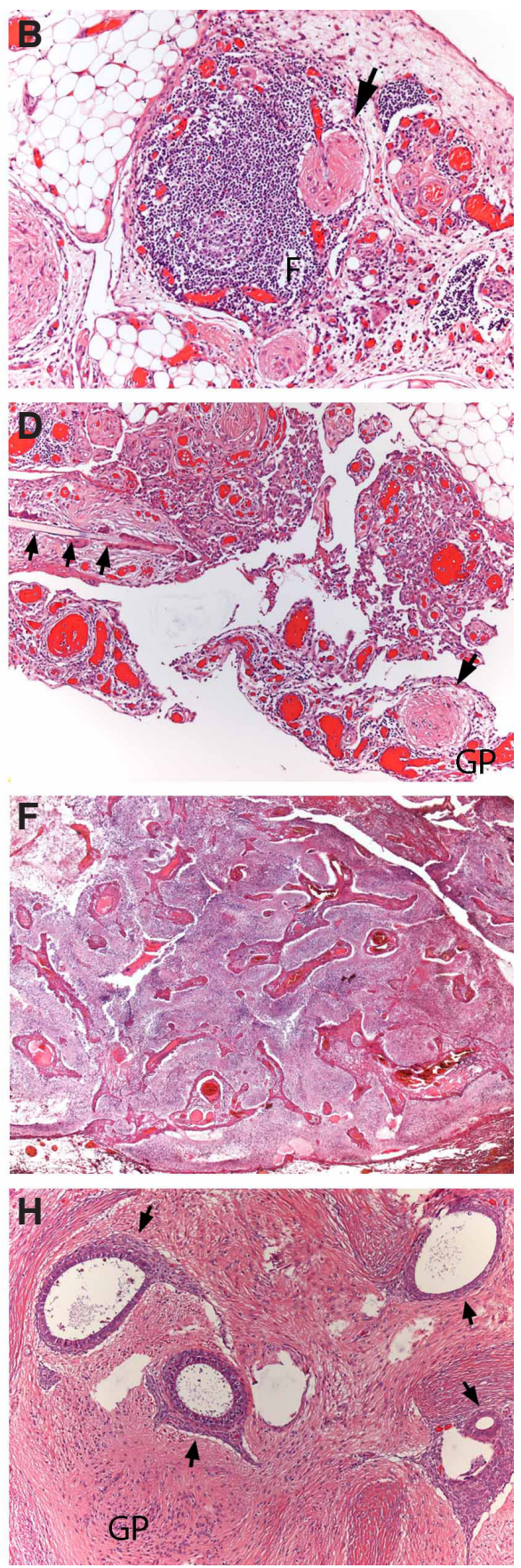
(Fig. 3A). All those features would indicate a teratoid maturation from embryonal, immature precursors from the ovarian tumour. Local differentiation would occur either spontaneously or induced by platin-based chemotherapy (Gibas et al., 1993; Kane et al., 2009; Yoon et al., 2012). Although most cases of implanted glial tissue mature spontaneously, chemotherapeutic conversion of neural immature cells into benign ones is the proposed mechanism for cases of growing teratoma syndrome associated with GP (Hsieh et al., 2009; Umekawa et al., 2005).

b) Shed keratin scales and hairs from the primary ovarian teratoma (Figs $4 C, D)$ are often associated with GP, representing a gross but evident marker of its origin in the ovary and its subsequent transport into the peritoneum through the capsule.

c) Cases showing lymph node involvement (Figs 3B) by foci mature glial, even in the absence of a peritoneal lesion (El Shafie et al., 1984; Heifetz et al., 1998; Perrone et al., 1986), would indicate a lymphatic transport of neural immature precursors that would eventually undergo full differentiation in the lymph nodes.

d) There are rare cases of GP associated with ventriculo-peritoneal shunts which would constitute a natural experiment of the implantative capacity into the peritoneum of glial cells present in the cerebrospinal fluid (Hill et al., 2000; Lobotesis et al., 2009; Lovell et al., 1989).

e) Some ovarian tumours such as struma ovarii (Karseladze et al., 1994) and well differentiated Sertoli cell neoplasms (Onida et al., 2010), are capable of producing highly differentiated nodular and miliary implantations in the peritoneum after tumour rupture or manipulation.

\section{Multifocal peritoneal metaplasia induced by growth factors}

In the last decade, genetic studies analysing multiple microsatellite markers in microdissected GP implants (Best et al., 2004; Ferguson et al., 2001; Kwan et al., 2004) have demonstrated that they have a heterozygosity pattern identical to the normal tissue and different from the coexistent ovarian teratoma, which is homozygous at the same loci. Although performed in only a few cases, these findings would imply a different genetic identity for the ovarian tumour and GP and thus challenge the classical implantative mechanism. This would favour the possibility of a metaplastic phenomenon from pluripotent subperitoneal cells, which would be a response to growth factors originating either from the coexistent teratoma (Ferguson et al., 2001), local macrophages (Gocht et al., $1995)$ or in the cerebrospinal fluid of ventriculoperitoneal shunts (Ferguson et al., 2001).

This would parallel a mechanism analogous to that giving rise to monoclonal peritoneal proliferations of such diverse tissues as smooth muscle (Guarch et al., 2001; Nogales et al., 1978) and epithelia such as endometrial (Clement et al., 2007), tubal- (Dallenbach-Hellweg et al., 1995; Donne et al., 1998) and endocervical (Liu et al., 2009), which would originate in stem cells with a capacity to develop into Müllerian cell lines under the influence of hormonal growth factors. This has been aptly called the secondary Müllerian system (Lauchlan et al., 1994), which is not restricted to the peritoneum, but also present in the urinary bladder (Donne et al., 1998), ureter (Nogales et al., 1999), pleura and even in the abdominal and axillary lymph nodes (Stolnicu et al., 2011).

The proposed local metaplastic peritoneal origin of GP would imply that stem cells would also be endowed with a further capacity to develop into non Müllerian lineages such as astroglia. The occasional association of PG and endometriosis (Fig. 4H) (Albukerk et al., 1979; Alexander et al., 2011; Bassler et al., 1982; Calder et al., 1994; Dworak et al., 1988; Killeen et al., 1997) would give partial support to this assumption. Endometriosis is a common condition currently considered to be of metaplastic origin in most cases (Clement et al., 2007). However, since pathogenetically related leiomyomatosis peritonealis disseminata, endosalpingiosis or endocervicosis have not been reported in association with GP, the association of endometriosis with GP may be coincidental, as endometriosis is a very common condition.

Taking into account both possibilities it would seem that an implantative origin from ovarian teratoma pluripotent precursors remains in most cases the more probable mechanism, although a metaplastic transformation from peritoneal stem cells under adequate growth factor stimulation is conceivable. We believe that this latter pathway would be restricted, however, to cases of GP that have a monotonous, monomorphic astroglial cell population, which would represent a selective cell lineage differentiation.

\section{Author's roles}

Francisco F. Nogales designed the study and participated in the analysis, execution and manuscript drafting and critical discussion. Isabel Dulcey retrieved archive material, performed the immunohistochemical and bibliographical analysis and participated in the manuscript drafting and critical discussion. Ovidiu Preda was responsible for the illustrations and immunohistochemistry.

\section{References}

ALBUKERK JN, BERLIN M, PALLADINO VC, SILVERMAN J (1979). Endometriosis in peritoneal gliomatosis. Arch Pathol Lab Med 103: 98-99.

ALEXANDER M, COPE N, RENNINSONJ, HONG A, SIMPSON RH, HIRSCHOWITZ $L$ (2011). Relationship between endometriosis, endometrioid adenocarcinoma, gliomatosis peritonei, and carcinoid tumor in a patient with recurrent ovarian teratoma. Int J Gynecol Pathol 30: 151-157.

BAHARI CM, LURIE M, SCHOENFELD A, JOEL-COHEN SJ (1980). Ovarian teratoma with peritoneal gliomatosis and elevated serum alpha-fetoprotein. $A m \mathrm{~J}$ Clin Pathol 73: 603-607.

BAKER PM, ROSAI J, YOUNG RH (2002). Ovarian teratomas with florid benign vascular proliferation: a distinctive finding associated with the neural component of teratomas that may be confused with a vascular neoplasm. Int $J$ Gynecol Pathol 21: 16-21.

BASSLER R, THEELE C, LABACH H (1982). Nodular and tumorlike gliomatosis peritonei with endometriosis caused by a mature ovarian teratoma. Pathol Res Pract 175: 392-403.

BEST DH, BUTZ GM, MOLLER K, COLEMAN WB, THOMAS DB (2004). Molecular analysis of an immature ovarian teratoma with gliomatosis peritonei and recurrence suggests genetic independence of multiple tumors. Int J Oncol 25: 17-25.

CALDER CJ, LIGHT AM, ROLLASON TP (1994). Immature ovarian teratoma with mature peritoneal metastatic deposits showing glial, epithelial, and endometrioid differentiation: a case report and review of the literature. Int J Gynecol Pathol 13: $279-282$.

CLEMENT PB (2007). The pathology of endometriosis: a survey of the many faces of a common disease emphasizing diagnostic pitfalls and unusual and newly appreciated aspects. Adv Anat Pathol 14: 241-260.

DADMANESH F, MILLER DM, SWENERTON KD, CLEMENT PB (1997). Gliomatosis peritonei with malignant transformation. Mod Pathol 10: 597-601.

DALLENBACH-HELLWEG G (1995). Critical commentary to "gliomatosis peritone combined with mature ovarian teratoma". Pathol Res Pract 191: 1037.

DE GRAAFF J, VAN DER HARTEN JJ (1980). Alpha-fetoprotein in ovarian teratoma with glial implants on the peritoneum. EurJObstet Gynecol Reprod Biol10:335-341.

DHINGRA KK, MANDAL S, KHURANA N, MANDAL AK (2007). Gliomatosis Perito- 
nei presenting as rectovaginal septum mass following recurrent mature ovarian teratoma. Acta Oncol 46: 1035-1036.

DONNE C, VIDAL M, BUTTIN X, BECERRA P, CARVIA R, ZULUAGAA, NOGALES FF (1998). Mullerianosis of the urinary bladder: clinical and immunohistochemical findings. Histopathology 33: 290-292.

DWORAK O, KNOPFLE G, VARCHMIN-SCHULTHEISS K, MEYER G (1988). Gliomatosis peritonei with endometriosis externa. Gynecol Oncol 29: 263-266.

EL SHAFIE M, FURAY RW, CHABLANI LV (1984). Ovarian teratoma with peritoneal and lymph node metastases of mature glial tissue: a benign condition. $J$ Surg Oncol 27: 18-22.

FERGUSON AW, KATABUCHI H, RONNETT BM, CHO KR (2001). Glial implants in gliomatosis peritonei arise from normal tissue, not from the associated teratoma. Am J Pathol 159: 51-55.

FORTT RW, MATHIE IK (1969). Gliomatosis peritonei caused by ovarian teratoma. $J$ Clin Pathol 22: 348-353.

GIBAS Z, TALERMAN A, FARUQI S, CARLSON J, NOUMOFF J (1993). Cytogenetic analysis of an immature teratoma of the ovary and its metastasis after chemotherapy-induced maturation. Int J Gynecol Pathol 12: 276-280.

GOCHT A, LOHLER J, SCHEIDEL P, STEGNER HE, SAEGER W (1995). Gliomatosis peritonei combined with mature ovarian teratoma: immunohistochemical observations. Pathol Res Pract 191: 1029-1035.

GONZALEZ-CAMPORAR, NOGALES FF, JR., DAVIDSON HG, MENDEZJA(1979). Case report: ultrastructure of mature neurogenic implants from ovarian immature teratoma. Histopathology 3: 233-240.

GUARCH R, PURAS A, CERES R, ISAAC MA, NOGALES FF (2001). Ovarian endometriosis and clear cell carcinoma, leiomyomatosis peritonealis disseminata, and endometrial adenocarcinoma: an unusual, pathogenetically related association. Int J Gynecol Pathol 20: 267-270.

HEIFETZ SA, CUSHING B, GILLER R, SHUSTER JJ, STOLAR CJ, VINOCUR CD, HAWKINS EP (1998). Immature teratomas in children: pathologic considerations: a report from the combined Pediatric Oncology Group/Children's Cancer Group. Am J Surg Pathol 22: 1115-1124.

HILL DA, DEHNER LP, WHITE FV, LANGER JC (2000). Gliomatosis peritonei as a complication of a ventriculoperitoneal shunt: case report and review of the literature. J Pediatr Surg 35: 497-499.

HOKAMAA, YAMASATO M, TOKUMINE N, NAKAMAB, MUTOY, TODAT, SHINGAKI Y, HIRAYAMA K (1991). Immature ovarian teratoma with peritoneal gliomatosis and elevated serum alpha-fetoprotein associated with a second mature teratoma Pediatr Surg Int 6: 448-450.

HSIEH YL, LIU CS (2009). Progression from an immature teratoma with miliary gliomatosis peritonei to growing teratoma syndrome with nodular gliomatosis peritonei. Pediatr Neonatol 50: 78-81.

KANE SV, KARPATEAA, BALM, JUVEKARSL, PAIPS (2009). Chemotherapy-induced neuronal maturation in sinonasal teratocarcinosarcoma--a unique observation. Head Neck Pathol 3: 31-36

KARLO C, LESCHKA S, DETTMER M, BREITENSTEIN S, STOLZMANN P (2009). Hepatic teratoma and peritoneal gliomatosis: a case report. Cases J 2: 9302.

KARSELADZE AI, KULINITCH SI (1994). Peritoneal strumosis. Pathol Res Pract 190: 1082-1085; discussion 1086-1088.

KILLEEN VB, REICH H, MCGLYNN F, VIRGILIO LA, KRAWITZMA, SEKEL L (1997). Pelvic gliomatosis within foci of endometriosis. JSLS 1: 267-268.

KWAN MY, KALLE W, LAU GT, CHAN JK (2004). Is gliomatosis peritonei derived from the associated ovarian teratoma? Hum Pathol 35: 685-688.

LAUCHLAN SC (1994). The secondary mullerian system revisited. Int J Gynecol Pathol 13: 73-79.

LIU JY, ZHENG J, LIAO SL (2009). Leiomyomatosis peritonealis disseminata associated with endocervicosis. Chin Med J (Engl) 122: 474-477.

LOBOTESIS K, JM UK-I, CROSS JJ, GILLARD JH, ANTOUN NM (2009). Gliomatosis peritonei associated with a ventriculo-peritoneal shunt. Clin Radiol 64: 95-99.

LOVELL MA, ROSS GW, COOPER PH (1989). Gliomatosis peritonei associated with a ventriculoperitoneal shunt. Am J Clin Pathol 91: 485-487.

MANN JR, GRAY ES, THORNTON C, RAAFAT F, ROBINSON K, COLLINS GS, GORNALL P, HUDDART SN, HALE JP, OAKHILLA (2008). Mature and immature extracranial teratomas in children: the UK Children's Cancer Study Group Experience. J Clin Oncol 26: 3590-3597.
MOROVICA, DAMJANOVI(2008). Neuroectodermal ovarian tumors: a brief overview. Histol Histopathol 23: 765-771.

MULLERAM, SONDGEN D, STRUNZR, MULLER KM (2002). Gliomatosis peritonei: a report of two cases and review of the literature. Eur J Obstet Gynecol Reprod Biol 100: 213-222.

NOGALES, F.F. (2003). The Pathology of Germ Cell Tumours. In Haines and Taylor's Obstetrical and Gynaecological Pathology (Eds. H. Fox and M.Wells). Churchill Livingstone, London, pp. 792.

NOGALES FF, AGUILARD (2002). Florid vascular proliferation in grade 0 glial implants from ovarian immature teratoma. Int J Gynecol Pathol 21: 305-307.

NOGALES, F.F. and AGUILAR, D. (1983). Neural Tissue in Human Teratomas. In In The Biology of Teratomas (Eds. I. Damjanov and D. Solter). Humana Press, Clifton N.J, pp. 183.

NOGALES FF, DULCEYI, PREDAO (2012). Germ cell tumors of the ovary: an update Arch Pathol Lab Med In Press:

NOGALES FF, JR., FAVARA BE, MAJOR FJ, SILVERBERG SG (1976). Immature teratoma of the ovary with a neural component ("solid" teratoma). A clinicopathologic study of 20 cases. Hum Pathol 7: 625-642.

NOGALES FF Jr., MATILLAA, CARRASCAL E (1978). Leiomyomatosis peritonealis disseminata. An ultrastructural study. Am J Clin Pathol 69: 452-457.

NOGALES FF JR., OLIVA HA (1974). Peritoneal gliomatosis produced by ovarian teratomas. Obstet Gynecol 43: 915-920.

NOGALES FF, ZULUAGA A, ARRABAL M, DHAKAL HP, AGUILAR D (1999). Mullerianosis of the ureter: a metaplastic lesion. J Urol 162: 2090-2091.

NOISA P, RAMASAMY TS, LAMONT FR, YU JS, SHELDON MJ, RUSSELLA, JIN X, CUI W (2012). Identification and characterisation of the early differentiating cells in neural differentiation of human embryonic stem cells. PLoS One 7:e37129.

NORRIS HJ, ZIRKIN HJ, BENSON WL (1976). Immature (malignant) teratoma of the ovary: a clinical and pathologic study of 58 cases. Cancer 37: 2359-2372.

O'CONNOR DM, NORRIS HJ (1994). The influence of grade on the outcome of stage I ovarian immature (malignant) teratomas and the reproducibility of grading. Int J Gynecol Pathol 13: 283-289.

ONIDA GA, BOSINCU L, DESSOLE S, NICOLAE A, PREDA O, COSSU-ROCCA P, ANEIROS-FERNANDEZ J, NOGALES FF (2010). Sertoli cell tumor with benign peritoneal implants associated with gonadoblastoma. Int J Gynecol Pathol 29: 423-426

PERRONE T, STEINER M, DEHNER LP (1986). Nodal gliomatosis and alphafetoprotein production. Two unusual facets of grade I ovarian teratoma. Arch Pathol Lab Med 110: 975-977

ROBBOY SJ, SCULLY RE (1970). Ovarian teratoma with glial implants on the peritoneum. An analysis of 12 cases. Hum Pathol 1: 643-653.

SHEFREN G, COLLIN J, SORIERO O (1991). Gliomatosis peritonei with malignant transformation: a case report and review of the literature. Am J Obstet Gyneco 164: 1617-1620; discussion 1620-1611.

STOLNICU S, PREDA O, KINGA S, MARIAN C, NICOLAU R, ANDREI S, NICOLAE A, NOGALES FF (2011). Florid, papillary endosalpingiosis of the axillary lymph nodes. Breast J 17: 268-272.

Thurlbeck W, Scully R (1960). Solid teratoma of the ovary. A clinicopathological analysis of 9 cases. Cancer 13: 804-811.

TORIKAI M, TAHARA H, KAJI T, SHIMONO R, YANO T, YOSHIOKA T, KAWAKAMI $\mathrm{K}$, TAKAMATSU H (2007). Immature teratoma of gallbladder associated with gliomatosis peritonei, a case report. J Pediatr Surg 42: E25-27.

TRABELSI A, CONAN-CHARLET V, LHOMME C, MORICE P, DUVILLARD P, SABOURIN JC (2002). [Peritoneal glioblastoma: recurrence of ovarian immature teratoma (report of a case)]. Ann Pathol 22: 130-133.

UMEKAWA T, TABATA T, TANIDA K, YOSHIMURA K, SAGAWA N (2005). Growing teratoma syndrome as an unusual cause of gliomatosis peritonei: a case report. Gynecol Oncol 99: 761-763.

YEO DM, LIM GY, LEE YS, SOHN DW, CHUNG JH (2010). Gliomatosis peritonei of the scrotal sac associated with an immature gastric teratoma. Pediatr Radiol 40: 1288-1292.

YOON NR, LEE JW, KIM BG, BAE DS, SOHN I, SUNG CO, SONG SY (2012). Gliomatosis peritonei is associated with frequent recurrence, but does not affect overal survival in patients with ovarian immature teratoma. Virchows Arch 461: 299-304. 


\section{Further Related Reading, published previously in the Int. J. Dev. Biol.}

Foetal germ cells: striking the balance between pluripotency and differentiation

Patrick Western

Int. J. Dev. Biol. (2009) 53: 393-409

The distribution and behavior of extragonadal primordial germ cells in Bax mutant mice suggest a novel origin for sacrococcygeal germ cell tumors

Christopher Runyan, Ying Gu, Amanda Shoemaker, Leendert Looijenga and Christopher Wylie Int. J. Dev. Biol. (2008) 52: 333-344

The germ cell - the mother of all stem cells.

P J Donovan

Int. J. Dev. Biol. (1998) 42: 1043-1050

Effects of growth factors on the differentiation of neural crest cells and neural crest cell-derivatives.

B K Hall and S Ekanayake

Int. J. Dev. Biol. (1991) 35: 367-387

Stimulation of tenascin expression in mesenchyme by epithelial-mesenchymal interactions.

$P$ Ekblom and E Aufderheide

Int. J. Dev. Biol. (1989) 33: 71-79

5 yr ISI Impact Factor $(2011)=2.959$

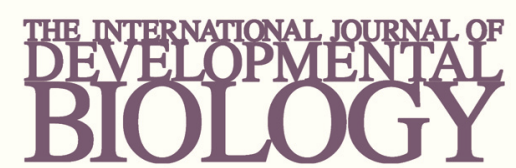

Volume 54 Nos. $6 / 7$

Special Issue
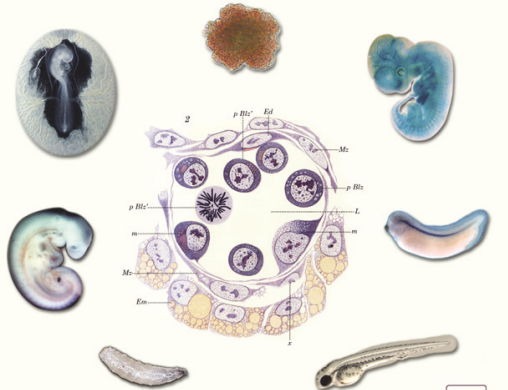

Developmental Hematopoiesis

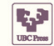

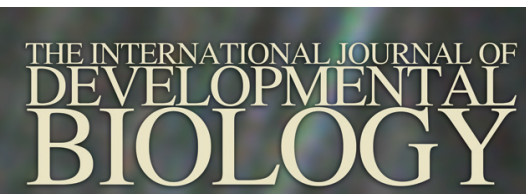

Volume 56 Nos. 1/2/3

Special Issue

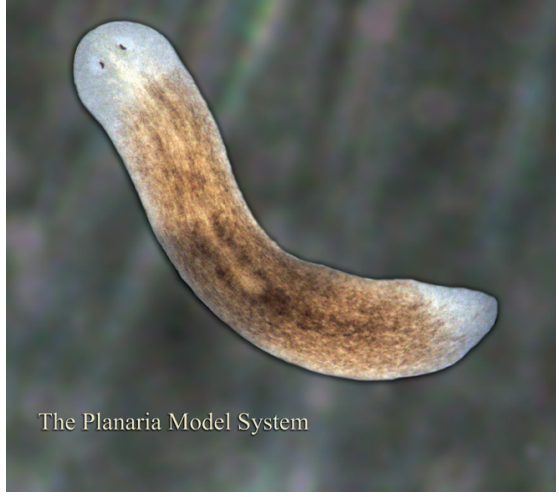

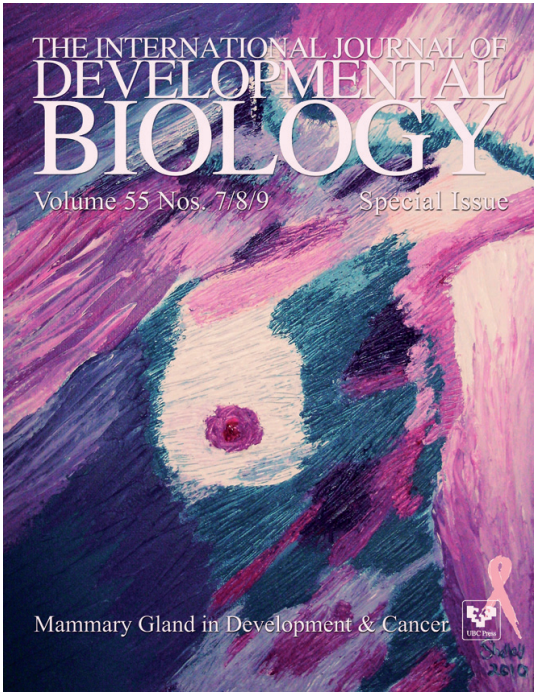

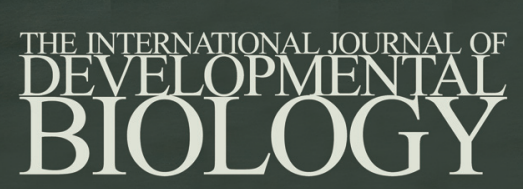

Volume 55 Nos. $4 / 5$

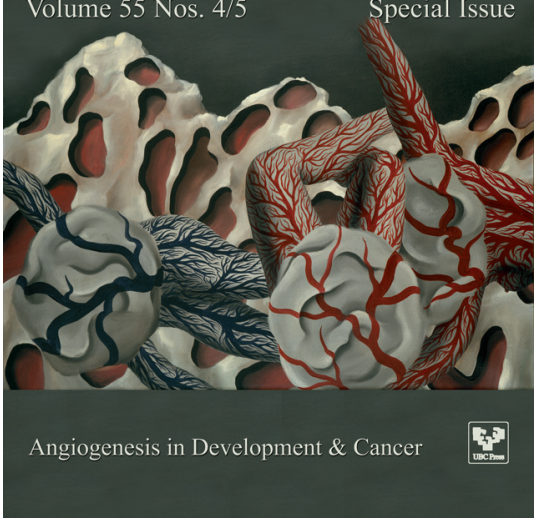

